\title{
Development of an arm support system to improve ergonomics in laparoscopic surgery: study design and provisional results
}

\author{
Benjamin Steinhilber • Sascha Hoffmann • Kristian Karlovic • Stefan Pfeffer • \\ Thomas Maier · Omar Hallasheh · Stephan Kruck • Robert Seibt • \\ Monika A. Rieger • Michael Heidingsfeld • Ronny Feuer • Oliver Sawodny • \\ Ralf Rothmund $\cdot$ Karl-Dietrich Sievert
}

Received: 26 May 2014/ Accepted: 4 November 2014/Published online: 25 December 2014

(C) The Author(s) 2014. This article is published with open access at Springerlink.com

\begin{abstract}
Background Laparoscopic surgery (LS) induces physical stress to the surgeon that is associated with an increased prevalence of musculoskeletal pain and injury in the shoulder-neck region. The aim of this research project is to develop an arm support system (ASsyst) that reduces physical stress and is applicable to various laparoscopic interventions and operation room settings.

Methods A systematic approach to develop an ASsyst started in October 2012 consisting of five consecutive steps. In step 1, 14 laparoscopic interventions were observed using
\end{abstract}

B. Steinhilber $(\bowtie) \cdot$ R. Seibt $\cdot$ M. A. Rieger

Institute of Occupational and Social Medicine and Health

Services Research, University Hospital Tübingen,

Tübingen, Germany

e-mail: benjamin.steinhilber@med.uni-tuebingen.de

R. Seibt

e-mail: robert.seibt@med.uni-tuebingen.de

M. A. Rieger

e-mail: Monika.Rieger@med.uni-tuebingen.de

S. Hoffmann $\cdot$ R. Rothmund

Department of Gynecology and Obstetrics, University Hospital

Tübingen, Tübingen, Germany

e-mail: sascha.hoffmann@med.uni-tuebingen.de

R. Rothmund

e-mail: Ralf.Rothmund@med.uni-tuebingen.de

K. Karlovic - S. Pfeffer - T. Maier

Institute for Engineering Design and Industrial Design (IKTD),

University of Stuttgart, Stuttgart, Germany

e-mail: kristian.karlovic@iktd.uni-stuttgart.de

S. Pfeffer

e-mail: stefan.pfeffer@iktd.uni-stuttgart.de

T. Maier

e-mail: thomas.maier@iktd.uni-stuttgart.de subjective and objective measures to determine key indicators for the conception of an ASsyst in LS. In step 2, an expert workshop was held to find and evaluate solutions to generate concepts for a support system based on the results of step 1 and general methods. During the third step, prototypes of ASsyst were tested in an experimental setting. Steps 4 and 5 are currently in process and include the final development of the ASsyst using the most promising concept for the evaluation during simulated LS.

Results Increased levels of physical stress were found in LS. Asymmetric strains were common. Three prototypes of ASsyst emerged from step 1 and 2. These prototypes were

O. Hallasheh · S. Kruck · K.-D. Sievert

Department of Urology, University Hospital Tübingen,

Tübingen, Germany

e-mail: halalsheh76@icloud.com

S. Kruck

e-mail: stephan.kruck@med.uni-tuebingen.de

K.-D. Sievert

e-mail: kd_sievert@hotmail.com

M. Heidingsfeld · R. Feuer · O. Sawodny

Institute for System Dynamics (ISYS), University of Stuttgart,

Stuttgart, Germany

e-mail: michael.heidingsfeld@isys.uni-stuttgart.de

R. Feuer

e-mail: ronny.feuer@isys.uni-stuttgart.de

O. Sawodny

e-mail: oliver.sawodny@isys.uni-stuttgart.de

K.-D. Sievert

Department of Urology, University Hospital Lübeck,

Schleswig-Holstein, Lübeck, Germany 
a cable construction with a noose for the lower arm, a support from below the elbow and a pneumatic vest supporting the upper arm. The experimental testing of these prototypes demonstrated reduced physical stress when compared to the unsupported environment. The support from below the elbow seemed to be the most practical in terms of implementation in various operation room settings and acceptance by surgeons. Step 4 and 5 are still in process. Conclusions Ergonomic problems have been identified in LS that could be addressed by an ASsyst. The concept of supporting the elbow from below has been found to be the most promising approach.

Keywords Laparoscopic surgery - Stress - Strain . Ergonomic $\cdot$ Human/robotic $\cdot$ Urology · Gynaecology \& obstetrics

Laparoscopic surgery (LS) is a common surgical method that provides several advantages to the patient. It is associated with reduced trauma, faster recovery, and reduced rate of failed septic wound healing, when compared to open surgery $[1,2]$. However, the biomechanical and mental strains placed on a surgeon when performing laparoscopic procedures are significantly higher, resulting in increased muscle fatigue [3], musculoskeletal pain [4], and injury [5]. In particular, the shoulder and neck region as well as the upper limbs are reported to be affected [6, 7]. Further confounding these statistics are the fact that workload intensity among surgeons [8] may escalate its adverse aspects and may even increase the risk of medical error.
Innovative technical developments such as roboticassisted laparoscopy appear to provide an opportunity to reduce physical stress on surgeons [9]. However, roboticassisted laparoscopy aims to further improve patient outcomes [10], not necessarily to improve ergonomics. It is therefore not surprising that muscle strain in the shoulderneck region continues to be reported, despite this new technology [11].

The aim of this research project is to develop an arm support system (ASsyst) that addresses the ergonomic issues in LS to reduce the amount of physical stress in the shoulder and neck region, as well as the upper limbs of the surgeon. This paper provides an overview of the steps in the development of ASsyst for LS and summarizes the major results of each step.

\section{Materials and methods}

Three university institutes, two clinical departments and two industrial partners participated in this project. Table 1 provides an overview of the five project steps along with the corresponding aim, method, and responsible project partners.

Step 1: investigate current situation

Data acquisition took place over 12 months at two surgical units (Urology and Gynecology) by analyzing surgeons and

Table 1 Consecutive steps of the research project

\begin{tabular}{|c|c|c|c|}
\hline Step & Aim & Methods & Responsible project partner \\
\hline 1 & Investigate current situation & $\begin{array}{l}\text { - Cross-sectional study on } \\
\text { laparoscopic interventions }\end{array}$ & $\begin{array}{l}\text { - Institute of Occupational and Social Medicine and Health } \\
\text { Services Research } \\
\text { - Institute for Engineering Design and Industrial Design } \\
\text { - Department of Gynecology and Obstetrics } \\
\text { - Department of Urology }\end{array}$ \\
\hline 2 & $\begin{array}{l}\text { Generate ideas for development } \\
\text { of a support system }\end{array}$ & - Expert workshop & $\begin{array}{l}\text { - All university institutes and departments } \\
\text { - All industrial partners }\end{array}$ \\
\hline 3 & $\begin{array}{l}\text { Test and evaluate elementary } \\
\text { concepts/prototypes }\end{array}$ & $\begin{array}{l}\text { - Experimental design with } \\
\text { data acquisition during } \\
\text { simulated laparoscopic } \\
\text { interventions }\end{array}$ & $\begin{array}{l}\text { - Institute of Occupational and Social Medicine and Health } \\
\text { Services Research } \\
\text { - Institute for Engineering Design and Industrial Design }\end{array}$ \\
\hline 4 & Develop arm support system & $\begin{array}{l}\text { - Hardware construction } \\
\text { and software development }\end{array}$ & $\begin{array}{l}\text { - Institute of Engineering Design and Industrial Design } \\
\text { - Institute for System Dynamics } \\
\text { - Industrial partners }\end{array}$ \\
\hline 5 & Evaluate arm support system & $\begin{array}{l}\text { - Cross-sectional study on } \\
\text { simulated laparoscopic } \\
\text { interventions with and } \\
\text { without an arm support } \\
\text { system }\end{array}$ & $\begin{array}{l}\text { - Institute of Occupational and Social Medicine and Health } \\
\text { Services Research } \\
\text { - Institute for Engineering Design and Industrial Design } \\
\text { - Department of Gynecology and Obstetrics } \\
\text { - Department of Urology }\end{array}$ \\
\hline
\end{tabular}


their operating procedures during LS as well as the operating room setup [12].

Fourteen standard laparoscopic surgical interventions were identified and observed in the urological clinic (nephrectomy, and partial nephrectomies; $n=4$ ) and the gynecological clinic (hysterectomy, ovariectomy; $n=10$ ). Laparoscopic procedures were similar within each of the two surgical units and were accomplished by six experienced surgeons (work experience $>10$ years, five righthanded and one left-handed males with four gynecological and two urological surgeons). In order to consider various sources of physical stress and physical complaints, a multiple measurement approach consisting of subjective and objective methods was used. Subjective methods included the NASA TLX [13] and the Nordic Questionnaire [14]. The NASA TLX questionnaire [13] determines the workload during a specific work task according to its six dimensions: physical demand, mental demand, temporal demand, performance, effort and frustration. This questionnaire provides an overall weighted workload score (OWWS) including all of the aforementioned dimensions and more detailed scores of every dimension. Higher scores indicate higher demands. The Nordic Questionnaire [14], a standard tool to assess prevalence of musculoskeletal disorders in specific regions of the body, was used to obtain information about musculoskeletal complaints of the last week and last 12 months. The Nordic Questionnaire was completed prior to the first LS and after every LS, the surgeon completed a NASA TLX questionnaire.

The objective methods included: a posture sensor placed on the dominant arm, bipolar surface electromyograms (SEMG) located on the right and left trapezius muscle (pars descendens), heart rate, and 2-dimensional (2D) video analysis.

\section{Posture sensor}

A three-dimensional gravimetric posture sensor (resolution: $0.1^{\circ}$ angle and $125 \mathrm{~ms}$ in time; maximum static error: $0.5^{\circ}$, THUMEDI, Thum-Jahnsbach, Germany) was placed at the lateral part of the dominant upper arm. This sensor measures the inclination toward the perpendicular line. In the case of an upright torso posture, as applied in this study, it is possible to measure the arm abduction angle as the inclination in the frontal plane.

SEMGs were measured at the trapezius pars descendens muscles of the dominant arm. The skin was prepared by cleansing with abrasive paste (Nurpreb ${ }^{\circledR}$ ) and shaving if there was excessive body hair. Self-sticking silver/silver chloride $(\mathrm{Ag} / \mathrm{AgCl})$ electrodes with an active diameter of $15 \mathrm{~mm}$ and an inter-electrode distance of $25 \mathrm{~mm}$ were used. Measurements were conducted with a PS11 measurement device (THUMEDI, Thum-Jahnsbach, Germany). The SEMG raw signal was sampled with $2048 \mathrm{~Hz}$, digitalized, and low and high-pass filtered $(12,650 \mathrm{~Hz}, 11$ th order). After the Fast Fourier Transformation (1024 FFT-points, BartlettWindow with $50 \%$ overlap), the electrical activity (EA) was calculated as the root mean square of the amplitude from the power spectrum. SEMGs were normalized to a submaximal static reference contraction with an ante-version of both straight arms holding a dumbbell $(2 \mathrm{~kg})$ in each hand [12].

\section{Videoanalysis}

The 2D video analysis was performed using three video cameras at different angles (back, front and side view) in order to observe the entire body of the surgeon and to obtain information about movements, postures, and the individual surgeons' procedures (Fig. 1). Two experts in ergonomy independently screened the recorded videos for extreme postures/movements and frequent unergonomic postures/movements. Significant postures based on expert ratings were then depicted using Dartfish-software (Fribourg, Switzerland).

Measures (arm posture, SEMG, and 2D video analysis) were recorded continuously throughout the laparoscopic interventions.

Step 2: generate ideas for development of a support system

An expert workshop, including all project partners, was conducted to generate a basic conceptual design of a support system. Due to the cooperative approach of this project, three of the investigated surgeons and the four evaluators who applied the measurements during step 1 , also participated in this workshop. During the initial expert workshop, the results of step 1 were presented and extensively discussed. The surgeons and evaluators contributed important information from the 'field' location. Concepts

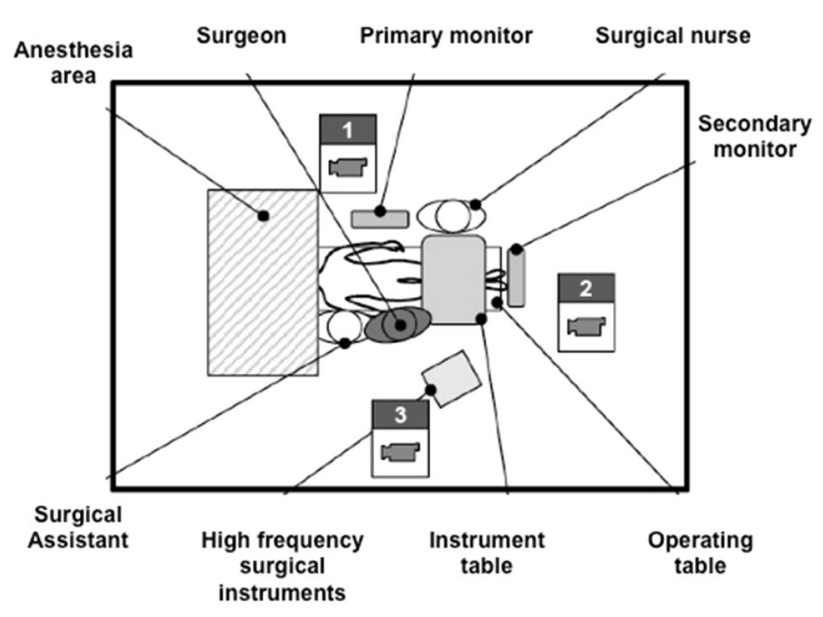

Fig. 1 Setup of the video analysis measurements in the operating room 
were then generated using different well-established engineering methods [15].

Step 3: test and evaluate elementary concepts/ prototypes

Three rudimentary prototypes were constructed and tested in an experimental setting by applying the same objective measures (posture sensor, SEMG, heart rate, and 2D video analysis) used during step 1. One gynecological surgeon performed the laparoscopic simulation exercise. The demonstration surgery was first performed without the support system and subsequently using each of the three prototypes. The simulation exercise was carried out using a pelvi-trainer and standard laparoscopic instruments, i.e., a part of the educational program of the European Society for Gynaecological Endoscopy (ESGE) the 'Laparoscopic Skills Testing and Training model (LASTT).' The setup included the standing position of the surgeon, monitor position, and height, as well as working height. The intention was to simulate the operating setup observed under real conditions in the gynecological clinic.

Step 4 and 5: development and evaluation of the prototype

Steps 1 through 3 yielded one prototype that supports the elbow from below. Using the same surgeons, step 5 of the project involves evaluating the system using the same multiple measurement approach in step 1.

\section{Results}

Step 1: investigate current situation

The results of the Nordic Questionnaire showed that surgeons from gynecology primarily indicated stress problems in the shoulder region, neck, and lower back region. Three subjects reported complaints in the neck region on 1-7 and 8-30 days within the last year and one subject complained about problems in the shoulder region that lasted up to more than 30 days within the last year. In urology data from the Nordic Questionnaire was not available. However, work ability of these two surgeons were not impaired. The OWWS of the NASA TLX was comparable between the two surgical units. The median OWWS of four surgeons from gynecology was 46 and the median of the two surgeons from urology was 38 .

The trapezius muscle showed significant differences in muscle activity in gynecology surgery with higher activity in the right trapezius muscle. No differences between the left and right shoulder muscle activity were found in urology. Our observation also revealed that the surgeons of the gynecological surgical unit had to operate predominantly with their right arm irrespective of handedness. Surgeons in urology appeared free to use their dominant arm to conduct the operation. However, trapezius activity was elevated in both sides of the body (Fig. 2). The categorization of right vs left hand and dominant vs nondominant trapezius muscle, respectively, is accounted for in the different gynecology and urology settings.

Posture sensor of the right upper arm in gynecology showed a high amount of arm abduction during LS with a median of $52^{\circ}$ and a range from $14^{\circ}$ to $147^{\circ}$ (Fig. 3).

The median heart rate was 85 (range 53-134) and did not change.

A 2D video analysis provided setting-related, task-related, and individual factors influencing surgeons' postures. Settings with the main screen positioned above eye level caused surgeons to tilt their head backward (Fig. 4A). Task-related changes forced surgeons to flex and rotate their body to keep the screen in sight (Fig. 4B). Surgeons also showed individual postures despite similar settings, tasks, and individual ways to support their posture, such as leaning against the operating table or resting their arms on the table (Fig. 4C). Further prolonged elevated arm postures were identified indicating static muscle strain in the shoulder-neck region.

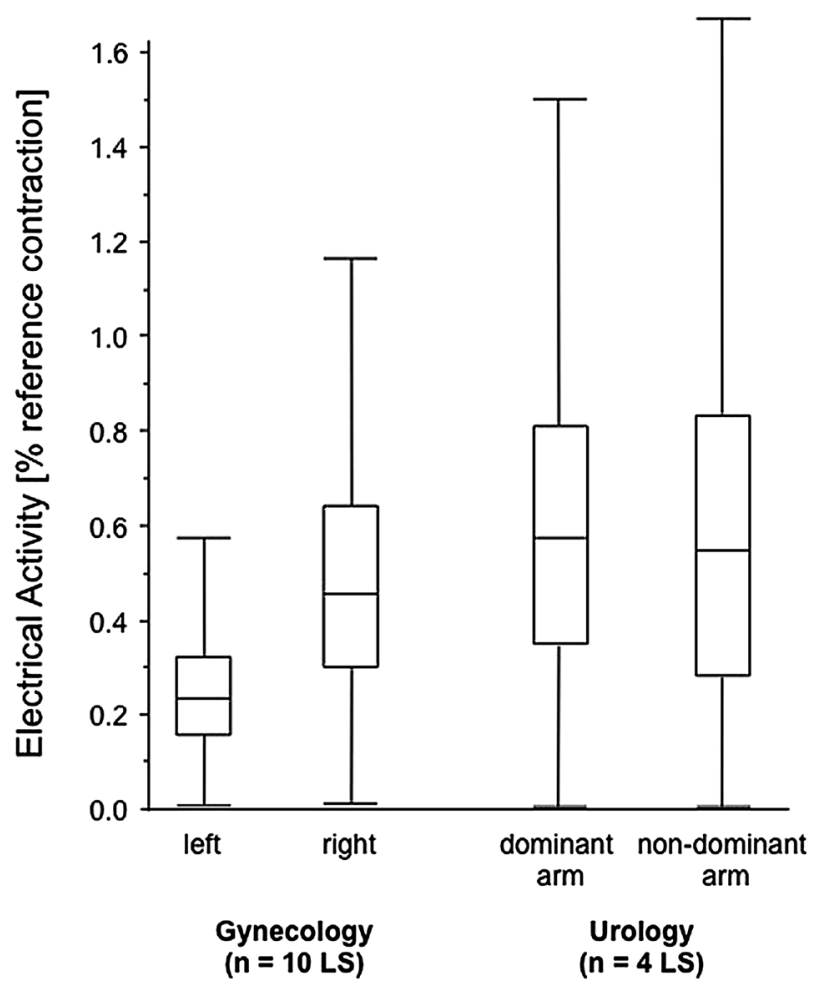

Fig. 2 Electrical activity of the trapezius muscle during laparoscopic surgery in gynecology and urology. The electrical activity is given as the percent of the reference contraction performed with a $90^{\circ}$ anteversion of both straight arms holding a $2-\mathrm{kg}$ dumbbell in each hand 
Fig. 3 Frequency distribution of the arm abduction angle in gynecological laparoscopic surgery

Fig. 4 Examples of representative body posture during laparoscopic surgery

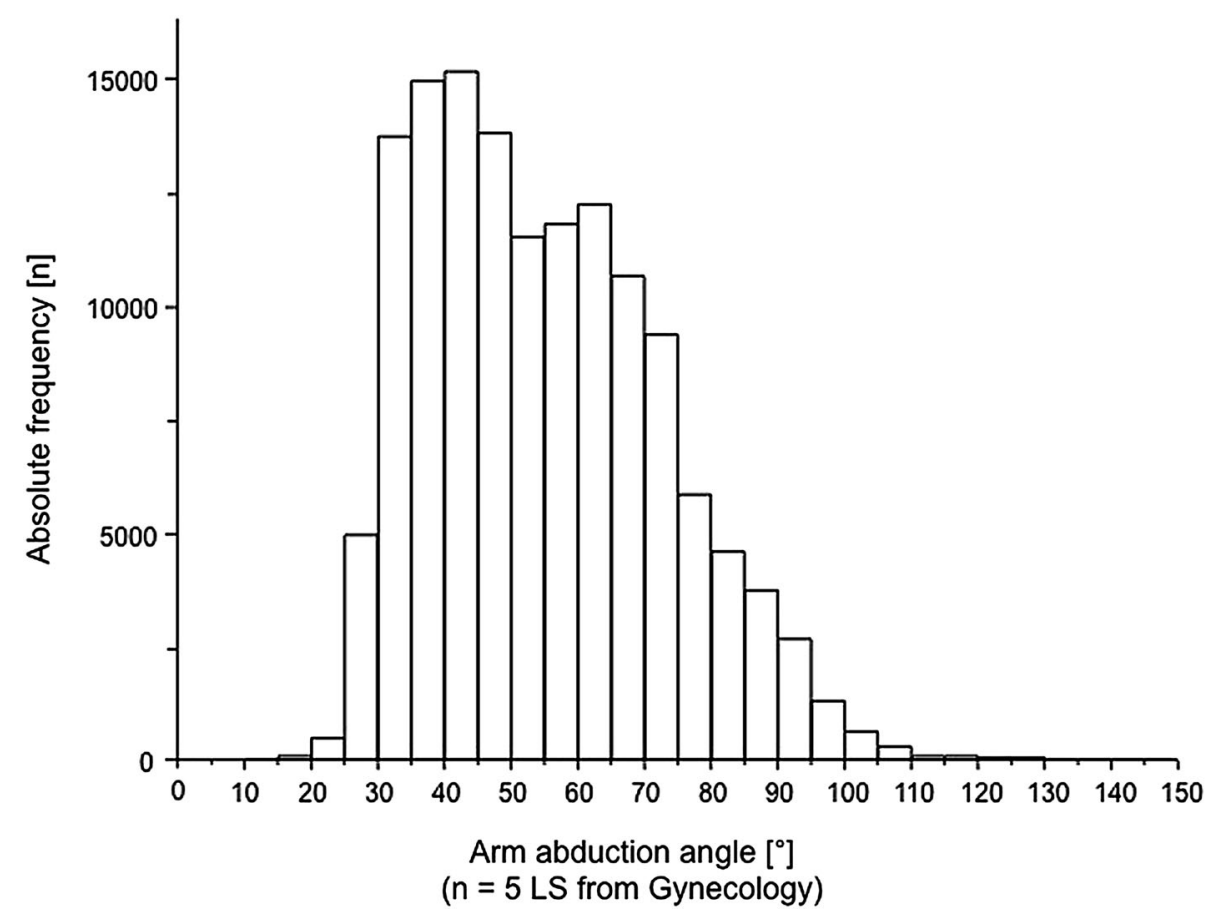

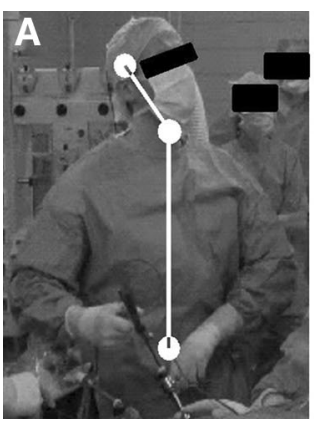

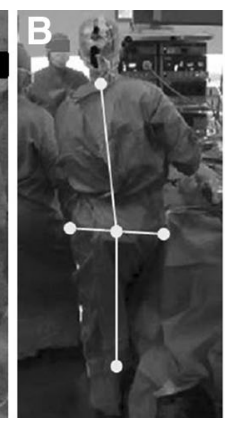

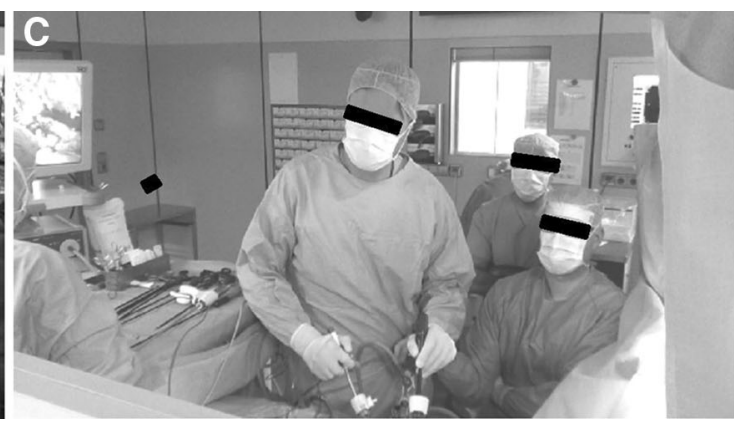

Step 2: generate ideas for development of a support system

The results of step 1 confirmed the findings reported in the literature $[4,16,17]$ regarding increased musculoskeletal pain and biomechanical stress in the shoulder-neck region. Furthermore several other aspects for ergonomic improvement during LS were observed such as the unergonomic position and placement of the monitor. However, recommendations for enhanced ergonomics monitor positioning were found in the literature [18]. Technical tools to reduce biomechanical stress in the shoulder-neck region are rare and may provide an opportunity to reduce physical stress that cannot be addressed by ergonomic monitor and table positioning only. Three basic concepts for the ASsyst were generated during the expert workshop. Concept A was a support for the entire lower arm that could either be used as a standalone device or construction fixed to the operating table. The second concept (concept B) was a pneumatic vest worn under the surgical work clothes. This vest could include air cushions that inflate on demand and support the upper arm of the surgeon. Concept $\mathrm{C}$ was a cable fixed to the ceiling that allows the surgeon to put their lower arm into a noose-like halter. These concepts resulted in three prototypes (Fig. 5).

Step 3: test and evaluate elementary concepts/ prototypes

When using each of the three prototypes, the results demonstrated lower trapezius muscle activity compared to the unsupported simulation exercise (Fig. 6). Trapezius activity during the unsupported exercise performance was comparable to the activity recorded during step 1 under actual clinical conditions. The posture sensor placed at the upper arm confirmed that the arm abduction angle was comparable between all trials and prototypes. 


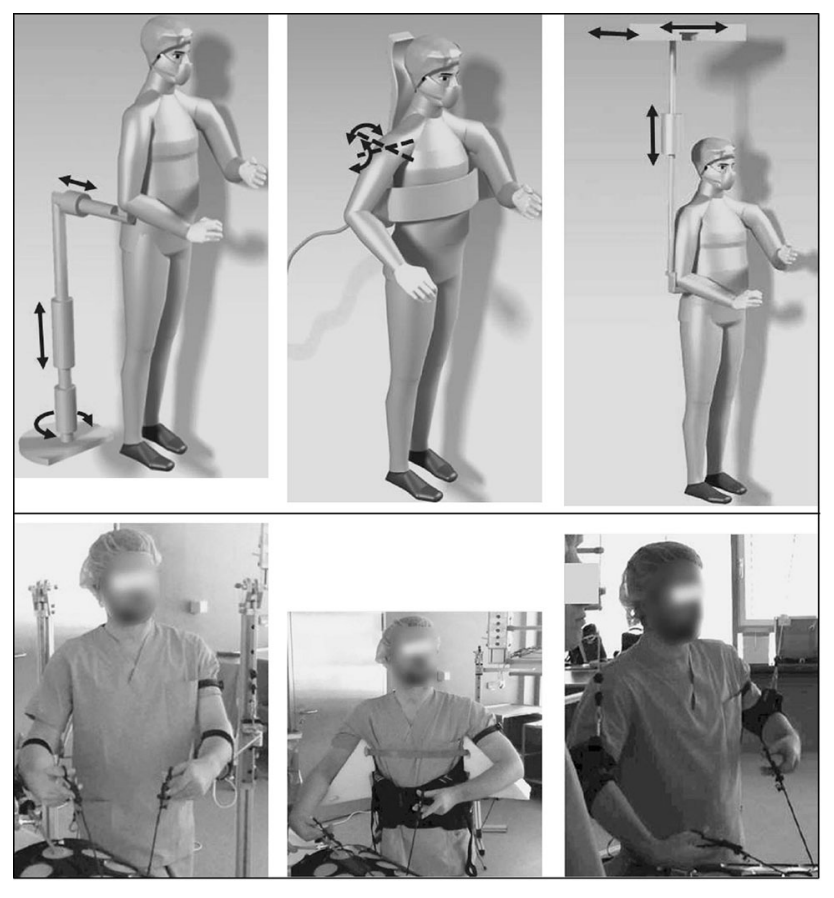

Prototype A

Prototype C
Fig. 5 Prototypes of three different concepts of a support system

Step 4 and 5: development and evaluation of the prototype

Currently in progress.

\section{Discussion}

LS is an established procedure in gynecology and urology with several limitations in workplace ergonomy. The research presented addresses ergonomic working conditions using a multi-modal concept for assessing the physicians' physical stress and strain during LS. Based on this analysis, an ASsyst was designed and evaluated. The interdisciplinary approach of this project unites work physiologists and ergonomists, construction engineers, manufacturers and potential users of the ASsyst, i.e., gynecologic or urologic surgeons. The investigation of typical live LS performed by a variety of experienced surgeons ensures high external validation of the evaluation measures that were performed during step 1 . Similarly, the evaluation of the three prototypes, based on simulated surgical laparoscopic procedures, led to high internal validity during step 3 . The methods applied, e.g., SEMG, arm abduction angle, heart rate analysis, questionnaires, and 2D video analysis are well known from other studies $[3,9,11,19,20]$, allowing a direct a comparison of the results.

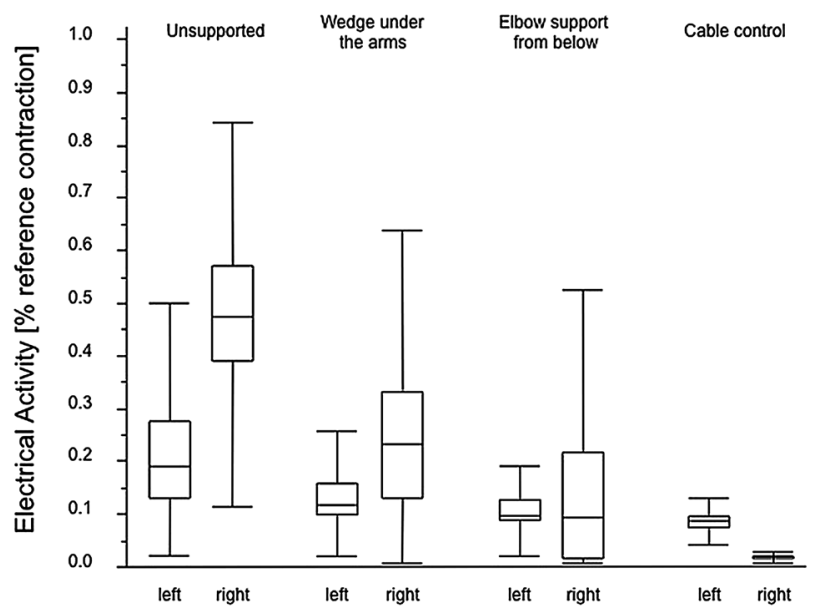

Fig. 6 Electrical activity of the trapezius muscle performing the simulated laparoscopic surgery with and without prototypes of different supporting systems (simulated laparoscopic surgery was performed predominantly with the right arm). The electrical activity is given as a percent of the reference contraction which is performed with a $90^{\circ}$ ante-version of both straight arms holding a 2-kg dumbbell in each hand

The results of step 1 of this research project confirmed the demand for ergonomic optimization in LS, which was previously reported $[3,19,21]$. Our results revealed supplementary information that characterized physical strains in the shoulder-neck region. There were increased and asymmetric levels of trapezius muscle activity, a substantial amount of arm abduction angle, and stressful head positions during the laparoscopic interventions. Further, the mean OWWS determined from the NASA TLX questionnaire was 38 (urology) and 46 (gynecology), which seems to be in the normal range for laparoscopic procedures [11, 22]. Lee et al. [11] found that roboticassisted laparoscopy decreased the OWWS through a change in the surgeons' body posture. However, trapezius activity was not influenced using robotic-assisted surgery. They also reported that surgeons without experience in robotic-assisted surgery even showed increased levels of trapezius muscle activity when performing robotic-assisted surgery, [11] which demonstrates that the setting for the robotic surgery is not yet optimal for the surgeon.

Our results, combined with findings in the literature, underline the importance of ergonomic tools for LS specifically designed to reduce physical strains in the surgeon's shoulder-neck region. In this context, a study on medical students indicated that a reduction of physical strain based on a subjective rating resulted in fewer errors during the performance of a laparoscopic task [23]. The concept of an ASsyst seems to address the strains in this specific body region. The experimental testing of three ASsyst prototypes during step 3 of this research project demonstrated a reduction in trapezius muscle activity. 
Although all prototypes decreased trapezius activity, the concept of an ASsyst that functions from below the elbow was favored based on the surgeons' preference. With regard to its acceptance and practicability in a realistic operating room setting, this approach seemed to be the most promising.

The findings of Jafri et al. in 2012 [24] indicated lower energy consumption and fewer medical errors during simulated minimal access surgery when the surgeon's arm was supported. It can be hypothesized that this ASsyst might be able to prevent surgeons from musculoskeletal injury in the shoulder-neck region and may also have a further benefit with regard to laparoscopic quality by reducing the medical errors caused by physical fatigue. These hypotheses will be further evaluated during step 4 and 5 of this research project.

Another added benefit that should be mentioned is that an ASsyst can easily be removed if the immediate conversion to standard LS is necessary, whether it is required in the event of an emergency or if the surgeon requires a different position. However, it has been reported that the conversion to standard LS due to medical emergency is very rare [25]. A review of the literature shows only few cases of malfunction of a well-known robotic-assisted laparoscopic system, the da Vinci system [26]. The robotic-assisted laparoscopic system has yet to be ergonomically evaluated and may lead to high physical strain in surgeons as well [11]. Further, there may even be an advantage of an ASsyst in comparison to robotic-assisted laparoscopy such as the da Vinci system, with regard to the reduction of physical stress and strain as well as patients' safety. Comparative data on physical strain with and without use of the ASsyst will be available after the completion of step 4 and 5 .

\section{Conclusions}

It has been demonstrated that there is a need for ergonomic optimization during LS. As the shoulder-neck region of the surgeon is exposed to major physical stress as well as other physical locations, an ASsyst is likely to improve ergonomics during LS. We were able to demonstrate that a specifically designed device can be used to supplement conventional laparoscopic settings and provide ergonomic advantages which reduce measurable stress and strain for the surgeon.

Acknowledgments This research project is part of the "Industry on Campus" program with the project number IOC-103 (Minister of Economy, Research and Art of the state of Baden Wuertemberg), induced by the inter-university center for medical technology Stuttgart-Tübingen with primary subject "Interactive based manipulator based assistants" funded by the universities, the industry partners TRUMPF Medical Technology and Festo AG \& Co. KG. The work of the Institute of Occupational and Social Medicine and Health Services Research Tübingen is supported by an unrestricted grant of the employers association of the metal and electric industry BadenWürttemberg (Südwestmetall). The funders had no role in study design, data collection and analysis, as well as preparation of the manuscript.

Disclosures The authors Benjamin Steinhilber, Sascha Hoffmann, Kristian Karlovic, Stefan Pfeffer, Thomas Maier, Omar Hallasheh, Stephan Kruck, Robert Seibt, Monika A. Rieger, Michael Heidingsfeld, Ronny Feuer, Oliver Sawodny, Ralf Rothmund, Karl-Dietrich Sievert have no conflicts of interest or financial ties to disclose.

Open Access This article is distributed under the terms of the Creative Commons Attribution License which permits any use, distribution, and reproduction in any medium, provided the original author(s) and the source are credited.

\section{References}

1. Uhrich ML, Underwood RA, Standeven JW et al (2002) Assessment of fatigue, monitor placement, and surgical experience during simulated laparoscopic surgery. Surg Endosc 16(4):635-639. doi:10.1007/s00464-001-8151-5

2. Lippert H, Koch A, Marusch F et al (2002) Offene vs. laparoskopische Appendektomie (Open vs. laparoscopic appendectomy). Chirurg 73(8):791-798

3. Quick NE, Gillette JC, Shapiro R et al (2003) The effect of using laparoscopic instruments on muscle activation patterns during minimally invasive surgical training procedures. Surg Endosc 17(3):462-465. doi:10.1007/s00464-002-8530-6

4. Berguer R, Forkey DL, Smith WD (1999) Ergonomic problems associated with laparoscopic surgery. Surg Endosc 13(5):466-468

5. Gofrit ON, Mikahail AA, Zorn KC et al (2008) Surgeons' perceptions and injuries during and after urologic laparoscopic surgery. Urology 71(3):404-407. doi:10.1016/j.urology.2007.07.077

6. Esposito C, El Ghoneimi A, Yamataka A et al (2013) Workrelated upper limb musculoskeletal disorders in paediatric laparoscopic surgery. A multicenter survey. J Pediatr Surg 48(8):1750-1756. doi:10.1016/j.jpedsurg.2013.01.054

7. Berguer R (1998) Surgical technology and the ergonomics of laparoscopic instruments. Surg Endosc 12(5):458-462

8. Bohrer T, Koller M, Schlitt HJ et al (2011) Workload and quality of life of surgeons. Results and implications of a large-scale survey by the German society of surgery. Langenbecks Arch Surg 396(5):669-676. doi:10.1007/s00423-011-0791-x

9. Hubert N, Gilles M, Desbrosses K et al (2013) Ergonomic assessment of the surgeon's physical workload during standard and robotic assisted laparoscopic procedures. Int J Med Robot 9(2):142-147. doi:10.1002/rcs.1489

10. O'Sullivan OE, O'Reilly BA (2012) Robot-assisted surgeryimpact on gynaecological and pelvic floor reconstructive surgery. Int Urogynecol J 23(9):1163-1173. doi:10.1007/s00192-0121790-3

11. Lee GI, Lee MR, Clanton T et al (2014) Comparative assessment of physical and cognitive ergonomics associated with robotic and traditional laparoscopic surgeries. Surg Endosc 28(2):456-465. doi:10.1007/s00464-013-3213-z

12. Pfeffer S, Hofmann A, Maier T et al (2013) Ergonomics of selected laparoscopic procedures-need for action? Biomed Tech. doi:10.1515/bmt-2013-4228

13. Hart S, Staveland L (1988) Development of NASA-TLX (Task Load Index): results of empirical and theoretical research in human mental workload. North Holland, Amsterdamm 
14. Kuorinka I, Jonsson B, Kilbom A et al (1987) Standardised Nordic questionnaires for the analysis of musculoskeletal symptoms. Appl Ergon 18(3):233-237

15. Beitz W, Pahl G, Grote K et al (2007) Engineering Design. A Systematic Approach. Springer-Verlag London, London

16. Stomberg MW, Tronstad S, Hedberg K et al (2010) Work-related musculoskeletal disorders when performing laparoscopic surgery. Surg Laparosc Endosc Percutan Tech 20(1):49-53. doi:10.1097/ SLE.0b013e3181cded54

17. Szeto GPY, Ho P, Ting ACW et al (2009) Work-related musculoskeletal symptoms in surgeons. J Occup Rehabil 19(2):175-184. doi:10.1007/s10926-009-9176-1

18. van Det MJ, Meijerink WJHJ, Hoff C et al (2009) Optimal ergonomics for laparoscopic surgery in minimally invasive surgery suites: a review and guidelines. Surg Endosc 23(6):1279-1285. doi:10.1007/s00464-008-0148-x

19. Berguer R, Rab GT, Abu-Ghaida H et al (1997) A comparison of surgeons' posture during laparoscopic and open surgical procedures. Surg Endosc 11(2):139-142

20. Pérez-Duarte FJ, Lucas-Hernández M, Matos-Azevedo A et al (2014) Objective analysis of surgeons' ergonomy during laparoendoscopic single-site surgery through the use of surface electromyography and a motion capture data glove. Surg Endosc 28(4):1314-1320. doi:10.1007/s00464-013-3334-4
21. Miller K, Benden M, Pickens A et al (2012) Ergonomics principles associated with laparoscopic surgeon injury/illness. Hum Factors 54(6): 1087-1092

22. Yin G, Han WK, Faddegon S et al (2013) Laparoendoscopic single site (LESS) in vivo suturing using a magnetic anchoring and guidance system (MAGS) camera in a porcine model: impact on ergonomics and workload. Urology 81(1):80-84. doi:10.1016/ j.urology.2012.09.018

23. Tse MA, Masters RSW, McManus AM et al (2008) Trunk muscle training, posture fatigue, and performance in laparoscopic surgery. J Endourol 22(5):1053-1058

24. Jafri M, Brown S, Arnold G et al (2013) Energy consumption during simulated minimal access surgery with and without using an armrest. Surg Endosc 27(3):971-977. doi:10.1007/s00464012-2544-5

25. Nezhat C, Lavie O, Lemyre M et al (2009) Robot-assisted laparoscopic surgery in gynecology: scientific dream or reality? Fertil Steril 91(6):2620-2622. doi:10.1016/j.fertnstert.2008.03. 070

26. Kim WT, Ham WS, Jeong W et al (2009) Failure and malfunction of da Vinci surgical systems during various robotic surgeries. Experience from six departments at a single institute. Urology 74(6):1234-1237 